\title{
Hypophosphatasia in adults: clinical spectrum and its association with genetics and metabolic substrates
}

Eveline Lefever a, Peter Witters ${ }^{b, c}$, Evelien Gielen ${ }^{\mathrm{d}, \mathrm{e}}$, Annick Vanclooster ${ }^{\mathrm{b}}$, Wouter Meersseman b, Eva Morava b,f,g, David Cassiman ${ }^{b, e, ~} \dagger$, Michaël R. Laurent d,e, $\dagger$, *

a Department of Internal Medicine, University Hospitals Leuven, Herestraat 49, 3000 Leuven, Belgium

${ }^{b}$ Centre for Metabolic Diseases, University Hospitals Leuven, Herestraat 49, 3000 Leuven, Belgium

c Department of Development and Regeneration, KU Leuven, Herestraat 49, 3000 Leuven, Belgium

d Center for Metabolic Bone Diseases, University Hospitals Leuven, Herestraat 49, 3000

Leuven, Belgium

e Department of Chronic Diseases, Metabolism and Aging (CHROMETA), KU Leuven, Herestraat 49, 3000 Leuven, Belgium

${ }^{\dagger}$ Hayward Genetics Center, Tulane University Medical School, New Orleans, LA, 70112, U.S.A.

${ }^{g}$ Clinical Genomics Department, Mayo Clinic, Rochester, MN, U.S.A.

† These authors share senior authorship.

* Corresponding author: Michaël R. Laurent, MD PhD, Herestraat 49, 3000 Leuven, Belgium

Tel.: +32 15505103 .E-mail: michael.laurent@uzleuven.be

Running title: Hypophosphatasia biomarkers in adults

Disclosure statement: PW and DC have received research support and consultancy fees from Alexion during the conduct of the study. DC also reports research grants from Shire and Genzyme, outside the submitted work. EG reports consultancy fees and non-financial support from Amgen, and consultancy fees from UCB, outside the submitted work. MRL has received consultancy fees from Alexion, Kyowa Kirin, Sandoz and UCB, and lecture fees and travel support from Amgen. All other authors report no conflicts of interest. 


\section{Abstract}

Background: Hypophosphatasia (HPP) is a rare metabolic bone disorder caused by mutations in the alkaline phosphatase (ALPL) gene, and characterized by low circulating alkaline phosphatase (ALP) levels and bone, muscle, dental and systemic manifestations. In this case series we investigate the clinical spectrum, genetic and biochemical profile of adult HPP patients from the University Hospitals Leuven, Belgium.

Methodology: Adults with HPP were identified through medical record review. Inclusion criteria were: 1 ) age $\geq 16$ years; 2 ) consecutively low ALP levels not explained by secondary causes; 3 ) one or more of the following supporting criteria: biochemical evidence of elevated enzyme substrates; subtrochanteric fractures, metatarsal fractures or other typical clinical features; family history of HPP; a known or likely pathogenic ALPL mutation.

Results: 19 patients met our inclusion criteria ( $n=2$ infantile, $n=6$ childhood, $n=10$ adultonset HPP and one asymptomatic carrier). Fractures and dental abnormalities were the most reported symptoms. Fatigue was reported in $n=7 / 19$ patients $(37 \%)$, three of which had previously been misdiagnosed as having chronic fatigue syndrome and/or fibromyalgia. Empirical pyridoxine therapy in four patients (without seizures) did not provide symptomatic relief. $\mathrm{N}=7 / 19$ patients (37\%) were inappropriately treated or planned to be treated with antiresorptive treatment. Two patients developed atypical femoral fractures following exposure to bisphosphonates and/or denosumab. Patients detected by screening were less severely affected, while patients with homozygous or compound heterozygous mutations had the most severe symptoms, significantly lower circulating ALP levels $(p=0.013)$ and significantly higher pyridoxal-5'-phosphate $(p=0.0018)$ and urinary phosphoethanolamine $(p=0.0001)$ concentrations.

Conclusions: Screening may detect mainly less severely affected individuals, which may nevertheless avoid misdiagnosis and inappropriate antiresorptive drug exposure. Patients with biallelic mutations had more severe symptoms, significantly lower ALP and higher substrate levels. Whether the latter finding has implications for the classification and treatment of HPP should be investigated further in larger cohorts.

Keywords: adults, alkaline phosphatase, fractures, hypophospatasia, phosphoethanolamine, pyridoxal-5'-phosphate 


\section{Introduction}

Hypophosphatasia (HPP) is a rare inborn disorder of bone and mineral metabolism due to mutations in the tissue-nonspecific alkaline phosphatase gene ( $A L P L)$, characterized by low plasma ALP levels (hypophosphatasemia) [1]. HPP is an extremely heterogeneous disease, depending on the type of mutation, mode of inheritance and age of onset [2]. Clinical manifestations range from defective mineralization (rickets, osteomalacia, stress fractures, atypical femoral fractures (AFFs), tooth loss) to systemic manifestations (pyridoxine-responsive seizures, respiratory failure from rachitic chest, nephrocalcinosis, kidney stones, muscle weakness, chronic pain, fatigue, etc.). In general, the most severe forms of HPP are associated with earlier (even perinatal) symptoms and diagnosis, while milder forms often present later during childhood or even in adulthood. Seven major forms are currently distinguished (Supplementary Table 1) [1], [3]. This classification focuses on skeletal manifestations and does not reflect the phenotypic continuum and the evolution of the disease throughout life.

HPP can be recessive or dominant [4]. Parents of children with recessive HPP may be mildly symptomatic; some may be considered to have adult HPP while others may be asymptomatic carriers. The diagnosis of HPP usually relies on low circulating ALP levels and is confirmed by increased ALP substrates: inorganic pyrophosphate $\left(\mathrm{PP}_{\mathrm{i}}\right)$, pyridoxal-5'-phosphate (PLP, the active metabolite of vitamin $\mathrm{B}_{6}$ ), and phosphoethanolamine (PEA) and, in most cases, also by genetic testing [5]. $\mathrm{PP}_{\mathrm{i}}$ measurement is not clinically available. PLP is a sensitive and specific biochemical marker for HPP, although great care is needed for preanalytic and analytic sample processing. Pyridoxine is used to relieve seizures in very severe HPP, but whether it can be effective for other symptoms like fatigue or muscle weakness is not known. Finally, amino acid measurements are routinely available in serum as well as urine, but PEA may be poorly standardized and appropriate cut-off levels for diagnosis are lacking in many settings. ALPL sequencing is of importance for genetic counseling, but may be false-negative in up to $\sim 5 \%$ of cases [5].

Correct diagnosis of HPP is important for several reasons. First, an enzymereplacement therapy has been approved and is available in some countries, albeit only for severe (childhood-onset) forms of HPP. Secondly, the risk of AFFs is markedly increased in adults with HPP who are erroneously treated with bisphosphonates [6], 
[7], [8]. Thirdly, a correct diagnosis of HPP may alleviate stress and search for alternative diagnoses for unexplained symptoms, e.g. metatarsal stress fractures, myopathy, chronic fatigue etc.

In this article we describe a case series of 19 HPP patients known at the University Hospitals of Leuven, Belgium. Specific research questions pertained to the correlation between clinical, biochemical and genetic features and pathway to diagnosis: we hypothesized that (1) family or laboratory database screening could have clinically relevant implications for identified patients, and (2) that ALP, PLP and PEA are more severely altered in clinically or genetically more severely affected individuals.

\section{Patients and Methods}

\subsection{Ethical approval}

The Ethical Committee for Clinical Research approved publication of this retrospective cohort study (Reference S60142). The need for individual written informed consent was waived.

\subsection{Data collection}

Patients with HPP known at the Centre for Metabolic Bone Diseases and the Centre for Metabolic Diseases were identified through medical record review. Subsequent to the introduction of a lower limit for plasma ALP in our hospital, a laboratory database search was performed for patients seen at the Metabolic Bone Diseases consultation from 2010 to 2015. For all patients with age-specific ALP values $\leq 2.5^{\text {th }}$ percentile, files and historical ALP levels were reviewed, and those with unexplained low ALP were invited for clinical re-evaluation, metabolic and genetic testing.

Our inclusion criteria were:

1. Age $\geq 16$ years on December 31, 2016;

2. Consistently low serum ALP levels (at least on two occasions) not explained by other causes [2], [9] (listed in Supplementary Table 2);

3. One or more of the following additional supporting elements:

a. elevated PEA or PLP; 
b. subtrochanteric femoral fractures, metatarsal fractures or other typical clinical features;

c. family history of HPP;

d. genetic testing showing a known or likely pathogenic $A L P L$ variant [2], [10].

Patients were classified as described in Supplementary Table 1. None of the patients had perinatal HPP or odontohypophosphatasia. Patients were diagnosed as asymptomatic carriers if they had low ALP with either raised metabolites and/or presence of a known pathogenic ALPL mutation, but without clinical symptoms.

We collected predefined demographical, clinical and biochemical data of the identified subjects, as well as bone densitometry results and results from genetic analyses from electronic medical records. In case multiple values were available, values closest to the time of first evaluation in our center were used (all patients were evaluated as adults).

\subsection{Biochemical measurements and genetic testing}

ALP (adult reference range: 35-105 U/L) was measured in heparin plasma using a standardized colorimetric assay in 2-amino-2-methyl-1-propanol buffer using calibration according to Schumann on a COBAS C702 (Hitachi, Roche®; test under accreditation ISO 15189) [11]. Random urine PEA was measured by standard amino acid liquid chromatography mass spectrometry using derivatisation with AccQTaglabelling on a Waters H-class Qda instrument [12]. The reference range from the Mayo Medical Laboratories was used (normal if $<48 \mathrm{nmol} / \mathrm{mg}$ creatinine or $<5.4 \mathrm{mmol} / \mathrm{mol}$ creatinine, based on $n=835$ individuals). For PLP (adult reference range 35-110 $\mathrm{nmol} / \mathrm{L}$ ), fasted morning EDTA whole-blood samples were immediately shielded from light, frozen at $-20^{\circ} \mathrm{C}$, and measured using reversed phase HPLC using fluorescent detection with pre- and post-column derivatisation at the General Medical Laboratory (AML) in Antwerp, Belgium.

Genetic testing was performed by accredited laboratories: the $\mathrm{CHU}$ Versailles, France (E. Mornet) until 2016, after which testing was performed at the Centre for Medical Genetics at the University Hospitals Ghent, Belgium.

\subsection{Bone densitometry}


Experienced and licensed technicians measured bone mineral density by dual-energy X-ray absorptiometry using a Hologic Discovery ${ }^{\circledR}$ (QRD-4500A, Hologic Inc, Marlborough, MA, USA)

\subsection{Statistical analysis}

We used Graph Pad Prism 7.04 for statistical analyses. Categorical variables are expressed as percentages of the total cohort. Continuous variables are presented with median and range values. We used chi-square test for categorical variables. For continuous variables, we used unpaired Student's $t$ test for comparing two groups and one-way ANOVA followed by multiplicity-adjusted Holm-Sidak's multiple comparisons post-test for more than two groups, respectively. Two-tailed $p<0.05$ was considered statistically significant.

\section{Results}

\subsection{Demographic and genetic characteristics}

We included 19 patients ( $n=10 / 19$ female, 53\%), median age 45 years (range 16-89) (Table 1). All patients were of Caucasian origin.

In 17 patients (89\%) an ALPL mutation was detected, whereas in 2 patients (11\%) no pathogenic variants were detected. One of these 2 patients had no elevated ALP substrates but has a son who also has consistently low ALP (Table 1, patient nr. 18). The other patient (nr. 17) had suggestive symptoms and elevated substrates. Among the patients with positive genetic testing, one patient born to consanguineous parents (first cousins) carried a homozygous ALPL mutation, two patients were compound heterozygous (with parents heterozygous in both cases), and 14 patients carried heterozygous mutations (Table 2). We identified 10 different point mutations in our population, 1 duplication and no deletions. Two of these 10 point mutations, c.361G>A (p.(Val121Met)) and c.538C >A (p.(His180Asn)) were novel mutations at the time of diagnosis. Interestingly, the c.361G>A mutation was found in 4 members of one family and 2 members of another family.

\subsection{Clinical features}

Eighteen patients $(95 \%)$ were considered symptomatic. Six patients $(38 \%)$ reported childhood symptoms and were classified as childhood-onset HPP, but were only 
diagnosed as adults. Among the 6 patients diagnosed by family screening, 5 were symptomatic at diagnosis. Two of these symptomatic patients reported chronic fatigue and one other reported chronic fatigue, chronic pain and muscle weakness.

Of the 13 symptomatic patients who weren't diagnosed by family screening, 7 (54\%) were correctly diagnosed with HPP initially and $6(46 \%)$ first received the diagnosis of osteoporosis. These latter patients were diagnosed with HPP after reviewing patients from the Metabolic Bone Centre in our hospital's central laboratory database, subsequent to the introduction of an ALP lower limit of normal. Two of these 6 patients (33\%) were treated with bisphosphonates, two of them (33\%) were treated with bisphosphonates and denosumab and one was planned to receive bisphosphonates, but never started. Of all 19 patients, $7(37 \%)$ were treated or planned to be treated with bisphosphonates alone $(n=5)$ or with bisphosphonates and denosumab $(n=2)$.

Fractures were the main symptom in 6 patients (33\%). Overall, fractures were the most common symptom, reported in 14 patients $(74 \%), 12$ of which had multiple fractures. The most common fracture sites were: wrist (5 patients), femur (4 patients), foot (4 patients, 2 of which had metatarsal stress fractures), humerus ( 3 patients), vertebra ( 3 patients) and ribs (3 patients). Three periprosthetic fractures were registered: one patient had a femoral periprosthetic fracture and one patient had a femoral and a humerus periprosthetic fracture. Four patients had femoral fractures, two of which had bilateral femoral fractures. AFFs (one-sided) were present in two patients. One of them had received bisphosphonates prior to the fracture, the other one had previously received bisphosphonates and denosumab.

Fatigue was reported in 7 patients (37\%), 5 of which were women. It was the presenting symptom in $n=4 / 19$ patients $(21 \%)$. The fatigue in 3 of these 4 patients was previously diagnosed as chronic fatigue syndrome. In the fourth patient (nr. 3, Table 1), the fatigue was disabling and led to school absenteeism. High-dose pyridoxine therapy (250 mg once daily for two months, 150x the U.S. recommended dietary allowance) was empirically initiated in three patients with chronic fatigue and one with a history of hemiplegic ischemic strokes. In one patient, on-treatment PLP concentrations were measured at $6389 \mathrm{nmol} / \mathrm{L}(\sim 58 \mathrm{x}$ the upper limit of normal, and higher than the highest PLP level in a patient with compound-heterozygous mutations). However, none of the patients reported symptomatic benefit (nor adverse effects) with this therapy and none continued it. 


\subsection{Subgroup analyses}

For subgroup comparisons, we divided our cohort in three different ways. First, we compared the clinically diagnosed HPP patients $(n=7)$, with the HPP patients from the Metabolic Bone Centre who were identified after introduction of an ALP lower reference level, i.e. case finding based on low ALP values $(n=6)$, and with the HPP patients diagnosed by family screening $(n=6)$ (Table $3, A$ ). Secondly, we divided our cohort into the following groups based on their mutation status: patients with homozygous/compound heterozygous mutations $(n=3)$, patients with heterozygous mutations ( $n=14)$ and patients with no mutations detected $(n=2)$ (Table 3, B). Thirdly, we distinguished the patients with infantile/childhood HPP $(n=8)$ from the patients with adult HPP ( $n=10)$, excluding one asymptomatic carrier (Table 3, C).

The clinically diagnosed HPP patients were younger at diagnosis (median: 27 years, range: $<6$ months -38 years) compared to those identified by ALP-based screening $(P=0.0004)$ or family screening $(P=0.0017)$. Clinically diagnosed HPP patients were also more often classified as infantile or childhood-onset HPP (chi-square, $\mathrm{P}=0.0007$ ). However, in clinically diagnosed patients, ALP and urinary PEA levels were not significantly different from patients diagnosed by laboratory or family screening (Table 3, A). Phenotypic expression in the clinically diagnosed group included symptoms not or less frequently seen in the other two groups: growth delay $(n=3)$, rickets $(n=2)$, nephrolithiasis $(n=2)$, epilepsy $(n=1)$ and chondrocalcinosis $(n=1)$.

In comparison to the HPP patients with heterozygous mutations, the HPP patients with homozygous/compound heterozygous mutations were younger at diagnosis (median: 1 year, range: $<6$ months -16 years) compared to those with heterozygous ( $\mathrm{p}=0.0019)$ or no ALPL mutation ( $\mathrm{p}=0.0321$ ) (Table $3, \mathrm{~B})$. The proportion of patients with pediatricvs. adult-onset HPP was not significantly different between the genetically defined groups. The patients with biallelic mutations had lower ALP ( $p=0.013$ vs. heterozygous and $p=0.017$ vs. no mutation patients), higher PLP ( $p=0.0018$ vs. heterozygous and $p=0.006$ vs. no mutation patients) and higher PEA levels ( $p<0.0001$ vs. heterozygous and $p=0.0001$ vs no mutation patients) (Table 3, B and Fig. 1A). The most frequent symptoms in the HPP group with homozygous/compound heterozygous mutations were fractures $(n=3)$, but the patients in this group also reported symptoms that were not present or less frequent in the other two groups: rickets $(n=2)$, nephrolithiasis $(n=2)$ 
and chondrocalcinosis $(n=1)$. No patient in the group with biallelic mutations were asymptomatic, compared to two patients of the heterozygous group.

In comparison to the patients with adult HPP, the patients with infantile/childhood HPP were younger $(p=0.0021$ ), and had lower serum ALP levels (median: $20 \mathrm{U} / \mathrm{L}$, range: $<5-30 \mathrm{U} / \mathrm{L}, \mathrm{p}=0.03$ ). As expected, they showed symptoms that were not present in the adult HPP group: growth delay $(n=4)$, rickets $(n=3$, see Table 3, C), nephrolithiasis $(n=2)$, epilepsy $(n=1)$ and chondrocalcinosis $(n=1)$. However, the difference in PLP levels and urinary PEA levels were not significant compared to those with adult-onset HPP (Table 3, C and Fig. 1B).

\subsection{General biochemical and bone mineral density results}

Serum calcium, phosphate and creatinine levels were obtained in all 19 patients. Serum 25-hydroxyvitamin $\mathrm{D}(25(\mathrm{OH}) \mathrm{D})$ and parathyroid hormone $(\mathrm{PTH})$ levels were available in 18 patients. $\mathrm{N}=7 / 19$ patients $(37 \%)$ received calcium and/or vitamin $\mathrm{D}$ supplements at the time of diagnosis. One patient had hypercalcemia and two patients had hyperphosphatemia (all without calcium or vitamin D supplements). One patient had elevated serum 25(OH)D under supplementation with calcium and vitamin $D$, as well as a slightly elevated PTH. Another patient had elevated serum PTH levels, whereas one patient (with a compound heterozygous mutation) had decreased serum PTH levels. No patient had renal insufficiency. No significant differences in calcium, phosphate, $25(\mathrm{OH})$ D or PTH were seen between the different groups (divided as in Table 3).

Bone densitometry results were available in 14 patients. The median lumbar spine Tscore was -2.1 [range (0.7)-(-4.4)] and the median femoral T-score was -1.8 (range (0.7)-(-3.2)). Three patients had a normal lumbar spine $\mathrm{T}$-score and one patient had a normal femoral neck T-score. None of the 19 patients had both normal lumbar and femoral neck T-scores. No significant differences in T-scores or Z-scores (data not shown) were seen between the different patient groups (divided as in Table 3).

\section{Discussion}

Despite growing interest in HPP over the past years many questions remain, for example concerning disease classification, natural history and the relationship 
between biomarkers and disease severity. Therefore, we decided to describe the adult HPP population (19 patients) known at our tertiary center.

Adult HPP often follows a mild course and is usually diagnosed in middle age [10], as was the case in our cohort. Still, of all patients diagnosed as adults, five reported symptoms in childhood and were consequently diagnosed with the childhood form. Our oldest patient was an 89-year-old woman. In her case, the diagnosis helped avert antiresorptive therapy as well as subsequent recognition of HPP and counselling in several of her children and grandchildren. In our cohort, all patients but one (i.e. 95\%) were symptomatic at diagnosis, which is higher than in some other series [13], [14]. In the Mayo Clinic series [10], up to $1 / 3^{\text {rd }}$ of patients were asymptomatic at diagnosis, although many had features suggestive of HPP. Therefore, 'symptomatic' may be considered a relative term that depends upon the duration of follow-up and how extensively symptoms are documented. Conversely, it can be challenging to determine whether symptoms like fractures, fatigue etc. are related to HPP or coincidental, since fatigue is common in the general population. Particularly in family screening, our findings may be somewhat confounded by ascertainment bias.

Genetic analysis was positive in 17 of our $19(89 \%)$ patients. This was higher than in previous case series [13], [14], [15], [16], probably because our patient selection was more clinically oriented. We found two new mutations (now listed in the ALPL mutation database), one of which (c.361G>A (p.(Val121Met)) was a novel mutation found in 6 patients from two independent families. In two patients, no mutation was detected. Cases with possible HPP symptoms and familial low serum ALP in the absence of elevated substrates or an ALPL mutation (patient 18, Table 1) provide a diagnostic conundrum and might, for example, carry another mutation in a gene mimicking HPP. It is still possible that patients with a negative genetic test carry an ALPL mutation because current genetic techniques allow the detection of up to $95 \%$ of the mutations in patients affected with HPP [17], [18].

Musculoskeletal pain is a recognized symptom in adult HPP [10] but fatigue has received little attention previously. Chronic fatigue was reported in 7 of our patients, and in 3 it was the presenting symptom for which they were previously diagnosed as having chronic fatigue syndrome. Thus, it can be useful to carefully review serum ALP levels in the work-up of generalized fatigue before labelling patients as having chronic fatigue syndrome or fibromyalgia, which remain diagnoses by exclusion. Considering 
the role of vitamin $B_{6}$ in the neurological symptoms of HPP, we wondered whether pyridoxine could be a cheap and safe alternative therapy for chronic fatigue or pain associated with adult-onset HPP. In our limited experience however, off-label pyridoxine therapy in four patients was not effective.

Given that there is still a lack of a lower reference range for ALP in many hospitals, the question arises whether identifying HPP patients by means of ALP-based screening is worthwhile [19], [20]. We found that a case finding or family screening strategy identified only mild HPP cases, who could nevertheless be considered symptomatic. Notably, three mildly to moderately symptomatic patients with positive genetic testing had low-normal ALP values (range 37-42 U/L) and one (patient 12) even had normal metabolites. We therefore suggest that in patients with low-normal ALP but suggestive clinical or family history, repeat ALP measurement and perhaps further metabolic, genetic testing or both should still be considered. Most patients detected by either screening strategy showed a positive attitude towards their diagnosis, although it caused clinically relevant anxiety in 1 out of 6 patients diagnosed by family screening and in 1 out of 6 patients diagnosed by lab-based screening. Secondly, 7 of our 19 patients $(37 \%)$ were inappropriately treated or planned to be treated with bisphosphonates and/or denosumab. Furthermore, $n=7 / 19$ patients $(37 \%)$ were treated with calcium- and/or vitamin D-supplements, which are also relatively contraindicated in HPP patients due to an increased risk of nephrolithiasis and hypercalcemia, unless at low doses when there is clear vitamin D deficiency [8].

Several cases of AFFs in patients with HPP exposed to bisphosphonates [6], [7], [8] have been reported. To our knowledge, we report here the first case of an AFF after exposure to both bisphosphonates and denosumab, in an HPP patient. Some believe that bisphosphonates are associated with AFFs via their PPi-like activity. This would imply that denosumab, which is also associated with AFFs but is structurally unrelated to $\mathrm{PP}$, could be a safe therapeutic options for patients with osteoporosis and HPP. However, we and others believe that the risk of AFFs is inherent to low bone turnover [6] and not necessarily related to a PPi-like effect with modern bisphosphonates at moderate doses. Still, it is possible that the AFF in our patient was related to her previous bisphosphonate exposure -in fact, denosumab might have prolonged the bisphosphonate retention in her skeleton. In any case, we can conclude that switching 
from bisphosphonates to denosumab, which is a common clinical strategy in osteoporosis nowadays, is unlikely to be helpful in HPP.

Interestingly, we observed that disease severity as well as the biochemical markers ALP, PLP and PEA were more closely predicted by mode of inheritance (recessive forms) than by age of onset (Table 3 and Fig. 1). Although the current classification is based on age of skeletal symptom onset, which correlates with disease severity, we believe that there is a need for further refinement focusing on disease severity regardless of age, for which genetic and biochemical markers are candidate biomarkers. In previous studies, clinical severity of HPP as well as more severely pathogenic mutations have been associated with lower ALP, higher PLP and higher PEA levels [10], [15, 16]. Because of the small study sample size however, our study was probably underpowered for some of the subgroup analyses.

Strengths of our study include the availability of genetic analyses in all patients and inclusion of patients with both infantile-, childhood- and adult-onset HPP. Our study also has several limitations, most importantly its small sample size and lack of statistical power. In comparison, several studies have correlated genetic and biochemical findings in $n=38-111$ adults with persistent hypophosphatasemia [13] [14] [15] [16]. Secondly, due to its retrospective design, there were clearly missing data from the medical records (which prevented us from e.g. reporting growth centiles, details during childhood or midparental height), and there may have been recall bias among the patients.

\section{Conclusions}

Establishing the diagnosis of HPP, not only in severe but also in apparently milder cases, is still important to avoid inappropriate treatment. Secondly, this diagnosis may alleviate the search for alternative explanations in patients with otherwise unexplained symptoms such as chronic fatigue or widespread pain. Our limited experience suggests that pyridoxine is not efficient for patients with adult-onset HPP and chronic fatigue or muscle pains. Finally, our findings add to a growing body of evidence supporting a correlation between genetic and biochemical markers and disease severity in HPP. Whether these insights can help refine the classification of HPP and 
predict which subjects will develop severe symptoms, requires further study in larger cohorts.

\section{Acknowledgement}

This work was partially supported by an unrestricted research grant from Alexion Pharma, which played no role in the study design, analysis or writing of the report.

\section{References}

1. Mornet E. Hypophosphatasia. Metabolism. 2018;82:142-55.

2. Linglart A, Biosse-Duplan M. Hypophosphatasia. Curr Osteoporos Rep. 2016;14(3):95-105.

3. Whyte MP, Zhang F, Wenkert D, McAlister WH, Mack KE, Benigno MC, et al. Hypophosphatasia: validation and expansion of the clinical nosology for children from 25 years experience with 173 pediatric patients. Bone. 2015;75:229-39.

4. Taillandier A, Domingues C, Dufour A, Debiais F, Guggenbuhl P, Roux C, et al. Genetic analysis of adults heterozygous for ALPL mutations. J Bone Miner Metab. 2017.

5. Mornet E. Hypophosphatasia. Orphanet J Rare Dis. 2007;2:40.

6. Whyte MP. Atypical femoral fractures, bisphosphonates, and adult hypophosphatasia. J Bone Miner Res. 2009;24(6):1132-4.

7. Sutton RA, Mumm S, Coburn SP, Ericson KL, Whyte MP. "Atypical femoral fractures" during bisphosphonate exposure in adult hypophosphatasia. J Bone Miner Res. 2012;27(5):987-94.

8. Genest F, Seefried L. Subtrochanteric and diaphyseal femoral fractures in hypophosphatasia-not atypical at all. Osteoporos Int. 2018;29(8):1815-25.

9. Connolly AM, Pestronk A, Planer GJ, Yue J, Mehta S, Choksi R. Congenital muscular dystrophy syndromes distinguished by alkaline and acid phosphatase, merosin, and dystrophin staining. Neurology. 1996;46(3):810-14.

10. Berkseth KE, Tebben PJ, Drake MT, Hefferan TE, Jewison DE, Wermers RA. Clinical spectrum of hypophosphatasia diagnosed in adults. Bone. 2013;54(1):21-7. 
11. Schumann G, Dominick HC, Hellmann D, Klauke R, Mockesch M, Stekel H, et al. Alkaline phosphatase activity: new assay for the Reflotron system. Results of the evaluation in eight clinical laboratories. Clin Chem Lab Med. 2001;39(1):71-8.

12. Salazar C, Armenta JM, Cortes DF, Shulaev V. Combination of an AccQ.Tagultra performance liquid chromatographic method with tandem mass spectrometry for the analysis of amino acids. Methods Mol Biol. 2012;828:13-28.

13. Tenorio J, Alvarez I, Riancho-Zarrabeitia L, Martos-Moreno GA, Mandrile G, de la Flor Crespo M, et al. Molecular and clinical analysis of ALPL in a cohort of patients with suspicion of Hypophosphatasia. Am J Med Genet A. 2017;173(3):60110.

14. Riancho-Zarrabeitia L, Garcia-Unzueta M, Tenorio JA, Gomez-Gerique JA, Ruiz Perez VL, Heath KE, et al. Clinical, biochemical and genetic spectrum of low alkaline phosphatase levels in adults. Eur J Intern Med. 2016;29:40-5.

15. Schmidt T, Mussawy H, Rolvien T, Hawellek T, Hubert J, Ruther W, et al. Clinical, radiographic and biochemical characteristics of adult hypophosphatasia. Osteoporos Int. 2017;28(9):2653-62.

16. McKiernan FE, Dong J, Berg RL, Scotty E, Mundt P, Larson L, et al. Mutational and biochemical findings in adults with persistent hypophosphatasemia. Osteoporos Int. 2017;28(8):2343-8.

17. Mornet E, Hofmann C, Bloch-Zupan A, Girschick H, Le Merrer M. Clinical utility gene card for: hypophosphatasia - update 2013. Eur J Hum Genet. 2014;22(4).

18. Mentrup B, Girschick H, Jakob F, Hofmann C. A homozygous intronic branchpoint deletion in the ALPL gene causes infantile hypophosphatasia. Bone. 2017;94:75-83.

19. Saraff V, Narayanan VK, Lawson AJ, Shaw NJ, Preece MA, Hogler W. A Diagnostic Algorithm for Children with Low Alkaline Phosphatase Activities: Lessons Learned from Laboratory Screening for Hypophosphatasia. J Pediatr. 2016;172:181$6 \mathrm{e} 1$.

20. McKiernan FE, Berg RL, Fuehrer J. Clinical and radiographic findings in adults with persistent hypophosphatasemia. J Bone Miner Res. 2014;29(7):1651-60. 
Table 1. Demographic, clinical and biochemical characteristics of the included patients.

\begin{tabular}{|c|c|c|c|c|c|c|c|c|}
\hline $\begin{array}{l}\text { Patient } \\
\text { number }\end{array}$ & $\begin{array}{l}\text { Age, } \\
\text { Sex }\end{array}$ & $\begin{array}{l}\text { Age at } \\
\text { diagnosis }\end{array}$ & $\begin{array}{l}\text { Symptoms } \\
\text { (presenting } \\
\text { symptom listed first) }\end{array}$ & $\begin{array}{l}\text { ALP, } \\
\text { U/L }\end{array}$ & $\begin{array}{l}\text { PEA, } \\
\text { mmol/mol } \\
\text { creatinine }\end{array}$ & $\begin{array}{l}\text { PLP, } \\
\text { nmol/L }\end{array}$ & $\begin{array}{l}\text { Gene- } \\
\text { tics }\end{array}$ & $\begin{array}{l}\text { Onset of } \\
\text { HPP }\end{array}$ \\
\hline $\begin{array}{l}\text { Median } \\
\text { (range) }\end{array}$ & & $\begin{array}{l}45(<0.5 \\
-89 \\
\text { years })\end{array}$ & & $\begin{array}{l}28 \\
(<5- \\
42)\end{array}$ & $\begin{array}{l}5 \\
(1-84)\end{array}$ & $\begin{array}{l}234 \\
(49- \\
5728)\end{array}$ & & \\
\hline 1 & $36 \mathrm{~F}$ & 1 year & $\begin{array}{l}\text { Rickets, growth delay, } \\
\text { AFF, non-union, } \\
\text { chondro-calcinosis, } \\
\text { kidney stone }\end{array}$ & $<5^{*}$ & $84^{*}$ & I & ** & Infantile \\
\hline $2 \mathrm{a}$ & $33 \mathrm{M}$ & $\begin{array}{l}<6 \\
\text { months }\end{array}$ & $\begin{array}{l}\text { Failure to thrive, } \\
\text { rickets, growth delay, } \\
\text { fractures, pseudo- } \\
\text { fractures, non-union, } \\
\text { kidney stones, early } \\
\text { tooth loss }\end{array}$ & $<5^{*}$ & $53^{*}$ & $5728^{*}$ & ** & Infantile \\
\hline 3 & $16 \mathrm{M}$ & 1 years & $\begin{array}{l}\text { Fractures, early tooth } \\
\text { loss, fatigue, chronic } \\
\text { widespread pain }\end{array}$ & $16^{*}$ & $34^{*}$ & $1706^{*}$ & ** & Childhood \\
\hline $4 \mathrm{~b},+$ & $69 \mathrm{~F}$ & 69 years & $\begin{array}{l}\text { Rickets, AFFs, growth } \\
\text { delay, vascular } \\
\text { calcifications }\end{array}$ & $20^{*}$ & $11^{*}$ & $196^{*}$ & * & Childhood \\
\hline 5 & $32 \mathrm{~F}$ & 32 years & Growth delay, epilepsy & $30^{*}$ & 3 & $185^{*}$ & * & Childhood \\
\hline 6 & $27 \mathrm{~F}$ & 27 years & $\begin{array}{l}\text { Chronic fatigue, } \\
\text { fractures }\end{array}$ & $25^{*}$ & 1 & 120 & * & Childhood \\
\hline 7 & $38 \mathrm{~F}$ & 38 years & $\begin{array}{l}\text { Fractures, early tooth } \\
\text { loss }\end{array}$ & $30^{*}$ & 4 & $180^{*}$ & * & Childhood \\
\hline 8 & $36 \mathrm{~F}$ & 36 years & $\begin{array}{l}\text { Fractures, chronic } \\
\text { arthralgia }\end{array}$ & $20^{*}$ & l & / & * & Childhood \\
\hline $9 \mathrm{a}, \dagger$ & $35 \mathrm{~F}$ & 35 years & $\begin{array}{l}\text { Chronic fatigue, } \\
\text { chronic pain, muscle } \\
\text { weakness }\end{array}$ & $12^{*}$ & 5 & $267^{*}$ & * & Adult \\
\hline $10 \mathrm{a}, \dagger$ & $58 \mathrm{~F}$ & 58 years & Chronic fatigue & 41 & $7^{*}$ & $306^{*}$ & * & Adult \\
\hline $11 \mathrm{~b}, \dagger$ & $77 \mathrm{M}$ & 77 years & $\begin{array}{l}\text { Fractures, early tooth } \\
\text { loss }\end{array}$ & $28^{*}$ & I & l & * & Adult \\
\hline $12 \mathrm{~b}, \dagger$ & $72 \mathrm{M}$ & 72 years & $\begin{array}{l}\text { Fractures, early tooth } \\
\text { loss, vascular } \\
\text { calcifications }\end{array}$ & 42 & 5 & 96 & * & Adult \\
\hline $13 \mathrm{~b}, \dagger$ & $45 \mathrm{~F}$ & 45 years & $\begin{array}{l}\text { Chronic fatigue, } \\
\text { fractures }\end{array}$ & $26^{*}$ & $7^{*}$ & I & * & Adult \\
\hline $14+$ & $64 \mathrm{M}$ & 64 years & Oligoarthritis & 37 & $7^{*}$ & $234^{*}$ & * & Adult \\
\hline $15+$ & $74 \mathrm{M}$ & 74 years & $\begin{array}{l}\text { Fractures, early tooth } \\
\text { loss, vascular } \\
\text { calcifications }\end{array}$ & $33^{*}$ & 5 & / & * & Adult \\
\hline $16+$ & $89 \mathrm{~F}$ & 89 years & Fractures & $14^{*}$ & $29^{*}$ & I & * & Adult \\
\hline $17+$ & $40 \mathrm{M}$ & 40 years & $\begin{array}{l}\text { Fractures, dental } \\
\text { abnormalities, short } \\
\text { stature }\end{array}$ & $34^{*}$ & 3 & $278^{*}$ & - & Adult \\
\hline $18+$ & $62 \mathrm{M}$ & 62 years & $\begin{array}{l}\text { Fractures, idiopathic } \\
\text { hypercalciuria, early } \\
\text { tooth loss }\end{array}$ & $31^{*}$ & 2 & 49 & - & Adult \\
\hline $19 \mathrm{a}, \dagger$ & $60 \mathrm{M}$ & 60 years & I & $17^{*}$ & 4 & $497^{*}$ & * & Carrier \\
\hline
\end{tabular}

$\mathrm{M}=$ male, $\mathrm{F}=$ female, $\mathrm{AFF}=$ atypical femoral fracture,$-=$ negative genetic testing. Normal reference ranges are: for ALP 35-105 U/L, for PEA $<5.4 \mathrm{mmol} / \mathrm{mol}$ creatinine and for PLP 35-110 nmol/L.

${ }^{\text {a }}$ Members of same family, proband $=$ patient 2 
b Members of same family, proband = patient 4

† Patients detected by family screening

+ Patients diagnosed after the introduction of a laboratory lower reference range for ALP and review of our patient database.

* Laboratory value outside of reference range, or positive genetic testing (heterozygous). ${ }^{* *}=$ biallelic mutations. 
Table 2. ALPL mutations identified in our cohort.

\begin{tabular}{|c|c|}
\hline Patient & Mutation type \\
\hline 1 & Homozygous: c.896T>C (p.(Leu299Pro)), exon 9 \\
\hline \multirow[t]{3}{*}{$2 \mathrm{a}$} & $\begin{array}{l}\text { Compound heterozygous: c.361G>A (p.(Val121Met)), exon } \\
5\end{array}$ \\
\hline & c.1268T>C (p.(Val423Ala)), \\
\hline & exon 11 \\
\hline \multirow[t]{3}{*}{3} & $\begin{array}{l}\text { Compound heterozygous: c.571G>A (p.(Glu191Lys)), exon } \\
6\end{array}$ \\
\hline & c. $1172 \mathrm{G}>\mathrm{A}($ p. $($ Arg391His $))$, \\
\hline & exon 10 \\
\hline $4 \mathrm{~b}$ & Heterozygous: c.361G>A (p.(Val121Met)), exon 5 \\
\hline 5 & Heterozygous: c. $1171 \mathrm{C}>\mathrm{T}$ (p.(Arg391Cys)), exon 10 \\
\hline 6 & Heterozygous: c.746G>T (p.(Gly249Val)), exon 7 \\
\hline 7 & Heterozygous: c.538C>A (p.(His180Asn)), exon 6 \\
\hline 8 & Heterozygous: c.395 C>T (p.(Ala132Val)), exon 5 \\
\hline $9 \mathrm{a}$ & Heterozygous: c.1268T>C (p.(Val423Ala)), exon 11 \\
\hline $10 \mathrm{a}$ & Heterozygous: c.361G>A (p.(Val121Met)), exon 5 \\
\hline $\begin{array}{l}11-13 \\
b\end{array}$ & Heterozygous: c.361G>A (p.(Val121Met)), exon 5 \\
\hline 14 & Heterozygous: c.1171C>T (p. (Arg391Cys)), exon 10 \\
\hline 15 & Heterozygous: c.1397C>T (p.(Pro466Leu)), exon 12 \\
\hline 16 & $\begin{array}{l}\text { Heterozygous: c.335_340dup (p. (Gly 112_Thr113dup)), } \\
\text { exon } 5\end{array}$ \\
\hline 17-18 & / \\
\hline $19 \mathrm{a}$ & Heterozygous: c.1268T>C (p.(Val423Ala)), exon 11 \\
\hline
\end{tabular}

${ }^{\text {a }}$ Members of same family, proband $=$ patient 2

${ }^{\mathrm{b}}$ Members of same family, proband $=$ patient 4 
Table 3. Comparisons of clinical and biochemical features between subgroups of patients according to (A) mode of diagnosis, (B) mode of inheritance, or (C) HPP classification.

\begin{tabular}{|c|c|c|c|c|c|c|c|c|}
\hline & $\begin{array}{l}\text { A. } \\
\text { Clinically } \\
\text { diagnosed } \\
\text { HPP }(n=7)\end{array}$ & $\begin{array}{l}\text { ALP-based } \\
\text { screening } \\
(n=6)\end{array}$ & $\begin{array}{l}\text { Family } \\
\text { screening } \\
(n=6)\end{array}$ & $\begin{array}{l}\text { B. } \\
\text { Biallelic } \\
\text { mutations }(n=3)\end{array}$ & $\begin{array}{l}\text { Heterozygous } \\
(n=14)\end{array}$ & $\begin{array}{l}\text { No mutation } \\
(n=2)\end{array}$ & $\begin{array}{l}\text { C. } \\
\text { Infantile/ } \\
\text { Childhood } \\
\text { HPP }(n=8)\end{array}$ & $\begin{array}{l}\text { Adult-onset } \\
\text { HPP }(n=10)\end{array}$ \\
\hline Women, n (\%) & $5(71 \%)$ & $2(33 \%)$ & $3(50 \%)$ & $1(33 \%)$ & $9(64 \%)$ & 0 & $6(75 \%)$ & $4(40 \%)$ \\
\hline $\begin{array}{l}\text { Age at diagnosis, median } \\
\text { (range) }\end{array}$ & $\begin{array}{l}27^{*}(<6 \\
\text { months }-38 \\
\text { years) }\end{array}$ & $\begin{array}{l}66.5(40-89 \\
\text { years })\end{array}$ & $\begin{array}{l}59(35-77 \\
\text { years })\end{array}$ & $\begin{array}{l}1^{*}(<6 \text { months }-16 \\
\text { years })\end{array}$ & $\begin{array}{l}59(27-89 \\
\text { years })\end{array}$ & $\begin{array}{l}52(40-62 \\
\text { years })\end{array}$ & $\begin{array}{l}29.5^{*}(<6 \\
\text { months-69 } \\
\text { years) }\end{array}$ & $\begin{array}{l}63(35-89 \\
\text { years })\end{array}$ \\
\hline \multicolumn{9}{|l|}{ HPP classification, n (\%) } \\
\hline Infantile & 2 (29\%) & 0 & 0 & $2(67 \%)$ & 0 & 0 & $2(25 \%)$ & I \\
\hline Childhood & $5(71 \%)$ & $1(17 \%)$ & 0 & $1(33 \%)$ & $5(36 \%)$ & 0 & $6(75 \%)$ & l \\
\hline Adult & 0 & $5(83 \%) *$ & $6(100 \%) *$ & 0 & $8(57 \%)$ & $2(100 \%)$ & / & $10(100 \%)$ \\
\hline Symptomatic, n (\%) & $7(100 \%)$ & $5(83 \%)$ & $3(50 \%)$ & $3(100 \%)$ & $10(71 \%)$ & $2(100 \%)$ & $8(100 \%)$ & $7(70 \%)$ \\
\hline \multicolumn{9}{|l|}{ Symptoms, $\mathrm{n}(\%)$} \\
\hline Rickets & 2 (29\%) & 0 & 0 & $2(67 \%)$ & 0 & 0 & $2(25 \%)$ & 0 \\
\hline Growth delay & $3(43 \%)$ & $1(17 \%)$ & 0 & $2(67 \%)$ & $2(14 \%)$ & 0 & $4(50 \%)$ & 0 \\
\hline Fractures & $6(86 \%)$ & $5(83 \%)$ & $3(50 \%)$ & $3(100 \%)$ & 9 (64\%) & $2(100 \%)$ & 7 (88\%) & $7(70 \%)$ \\
\hline Epilepsy & $1(14 \%)$ & 0 & 0 & 0 & $1(7 \%)$ & 0 & $1(13 \%)$ & 0 \\
\hline Chondrocalcinosis & $1(14 \%)$ & 0 & 0 & $1(33 \%)$ & 0 & 0 & $1(13 \%)$ & 0 \\
\hline Nephrolithiasis & $2(29 \%)$ & 0 & 0 & $2(67 \%)$ & 0 & 0 & $2(25 \%)$ & 0 \\
\hline Hypercalciuria & 0 & $1(17 \%)$ & 0 & 0 & 0 & $1(50 \%)$ & 0 & $1(10 \%)$ \\
\hline Dental abnormalities & $3(43 \%)$ & $3(50 \%)$ & $2(33 \%)$ & $2(67 \%)$ & $4(29 \%)$ & $2(100 \%)$ & $3(38 \%)$ & $5(50 \%)$ \\
\hline Vascular calcifications & 0 & $2(33 \%)$ & $1(17 \%)$ & 0 & $3(21)$ & 0 & $1(13 \%)$ & $2(20 \%)$ \\
\hline $\begin{array}{l}\text { Fatigue and/or muscle } \\
\text { weakness }\end{array}$ & $3(43 \%)$ & $1(17 \%)$ & $3(50 \%)$ & $1(33 \%)$ & $5(36 \%)$ & $1(50 \%)$ & $3(38 \%)$ & $4(40 \%)$ \\
\hline \multicolumn{9}{|l|}{$\begin{array}{l}\text { Biochemistry, median } \\
\text { (range) }\end{array}$} \\
\hline ALP & $20(<5-30)$ & $32(14-37)$ & $27(12-42)$ & $<5^{\star}(<5-16)$ & $27(12-42)$ & $32.5(31-34)$ & $20^{*}(<5-30)$ & $32(12-42)$ \\
\hline PLP & $\begin{array}{l}185(120- \\
5728)\end{array}$ & $196(49-234)$ & $286.5(96-497)$ & $\begin{array}{l}3717^{*}(1706- \\
5728)\end{array}$ & $196(96-497)$ & $\begin{array}{l}163.5(49- \\
278)\end{array}$ & $\begin{array}{l}190.5(120- \\
5728)\end{array}$ & $\begin{array}{l}250.5(49- \\
306)\end{array}$ \\
\hline PEA & $19(1-84)$ & $5(2-11)$ & $5(4-7)$ & $53^{*}(34-84)$ & $5(1-11)$ & $2.5(2-3)$ & $11(1-84)$ & $5(2-7)$ \\
\hline
\end{tabular}



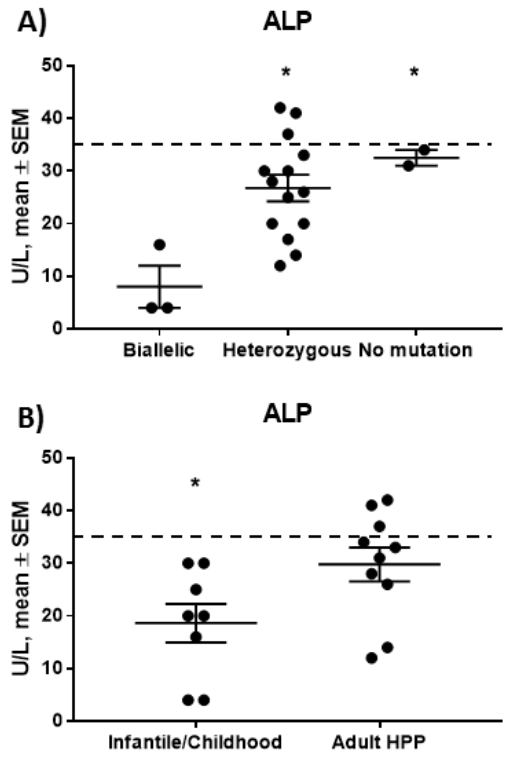

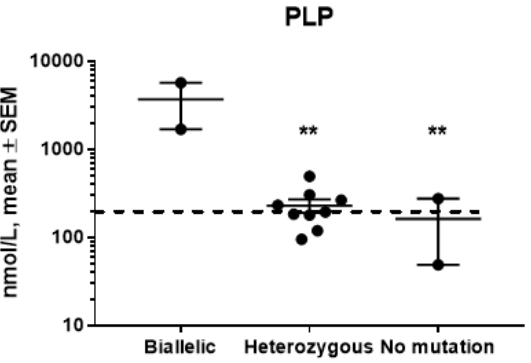

PLP

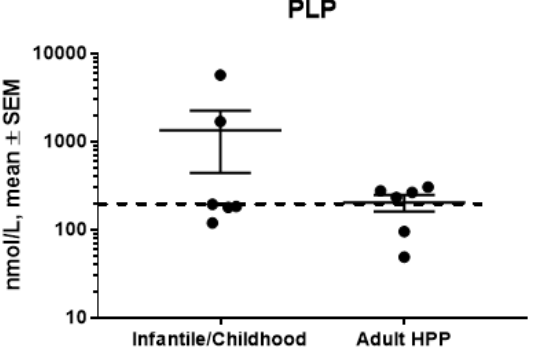

PEA

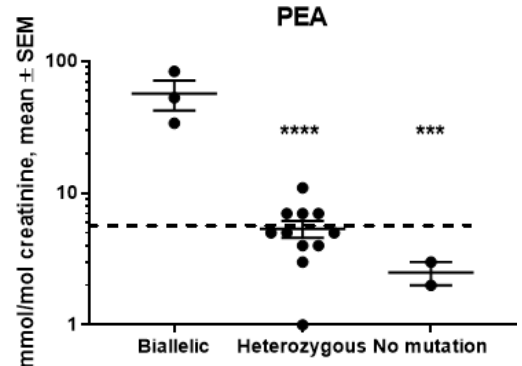

PEA

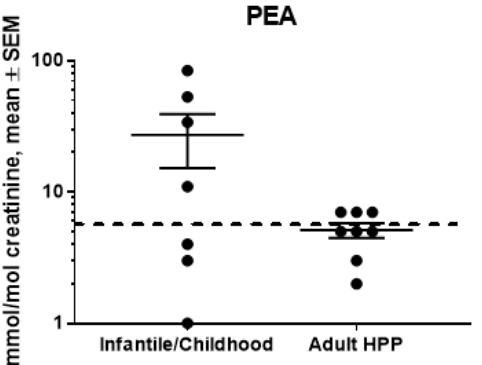

Fig. 1. Comparison of ALP, PLP and PEA levels between (A) patients with biallelic, heterozygous, and no ALPL mutations, and (B) patients with infantile- or childhoodonset vs. adult-onset HPP. ${ }^{*}=p<0.05,{ }^{* *}=p<0.01,{ }^{* * * *}=p<0.0001$. Horizontal dotted lines indicate the lower (for ALP) or higher (for PLP and PEA) reference ranges for the respective assays. 